\title{
Factors influencing dyslipidemia in statin-treated patients in Lebanon and Jordan: results of the Dyslipidemia International Study
}

This article was published in the following Dove Press journal:

Vascular Health and Risk Management

7 May 2014

Number of times this article has been viewed

\author{
Sami T Azar' \\ Hadi Abu Hantash ${ }^{2}$ \\ Selim Jambart ${ }^{3}$ \\ Mohamed M El-Zaheri ${ }^{4}$ \\ Rachoin Rachoin ${ }^{5}$ \\ Amal Chalfoun ${ }^{6}$ \\ Layla Lahoud ${ }^{6}$ \\ Osama Okkeh ${ }^{2}$ \\ Peter Bramlage ${ }^{7}$ \\ Philippe Brudi ${ }^{8}$ \\ Baishali M Ambegaonkar ${ }^{8}$ \\ 'American University of Beirut \\ Medical Center, Beirut, Lebanon; \\ ${ }^{2}$ Istishari Hospital, Amman, Jordan; \\ ${ }^{3}$ St Joseph University Faculty of \\ Medicine, Beirut, Lebanon; ${ }^{4}$ Jordan \\ Hospital, Amman, Jordan; ${ }^{5}$ Notre \\ Dame des Secours Hospital, Jbeil, \\ Lebanon; 'MSD Levant, Beirut, \\ Lebanon; ${ }^{7}$ Institut für Pharmakologie \\ und präventive Medizin, Mahlow, \\ Germany; ${ }^{8}$ Merck and Co, Inc., \\ Whitehouse Station, NJ, USA
}

Background: Cardiovascular disease is the leading cause of death and disability worldwide. Therefore, as part of the Dyslipidemia International Study (DYSIS), we have analyzed the prevalence of lipid abnormalities and risk factors for dyslipidemia in statin-treated patients in Lebanon and Jordan.

Methods: This cross-sectional, multicenter study enrolled 617 patients at 13 hospitals in Lebanon and Jordan. Patients were at least 45 years old and had been treated with statins for at least 3 months. Multivariate logistic regression analysis was used to determine patient characteristics contributing to dyslipidemia during statin therapy.

Results: Our findings indicated that $55.9 \%$ of statin-treated patients (mean age 60.3 years, $47 \%$ female) in Lebanon and Jordan did not achieve goal levels for low-density lipoprotein cholesterol which were dependent on Systematic Coronary Risk Evaluation (SCORE) risk, and 70\% of patients (76\% men and $63.3 \%$ of women) were at very high cardiovascular risk. Low-density lipoprotein cholesterol goals were not achieved in $67.2 \%$ of those with very high cardiovascular risk. The most commonly prescribed statin was atorvastatin $(44.6 \%)$, followed by simvastatin (27.7\%), rosuvastatin $(21.2 \%)$, fluvastatin $(3.3 \%)$, pravastatin $(3 \%)$, and lovastatin $(0.2 \%)$. Approximately half of the population was treated with a statin dose potency of 4, equaling $40 \mathrm{mg}$ of simvastatin. In Lebanon and Jordan, the strongest independent associations with low-density lipoprotein cholesterol not at goal were current smoking (odds ratio [OR] 1.96; 95\% confidence [CI] 1.25-3.08), diabetes mellitus (OR 2.53; 95\% CI 1.70-3.77), and ischemic heart disease (OR 2.26; 95\% CI 1.45-3.53), while alcohol consumption was associated with reduced risk (OR 0.12; 95\% CI 0.03-0.57).

Conclusion: We observed that many patients in Lebanon and Jordan experienced persistent dyslipidemia during statin treatment, supporting the notion that novel lipid-lowering strategies need to be developed. Also, social programs aimed at combating the extremely high rates of tobacco use and obesity in Lebanon and Jordan are critical for combating cardiovascular disease in these countries.

Keywords: cardiovascular disease, lipid abnormalities, statins, low-density lipoprotein cholesterol

\section{Introduction}

The World Health Organization has estimated that cardiovascular disease (CVD) accounted for more than $30 \%$ of deaths worldwide in 2008, and by 2030, almost 25 million people are predicted to die as a result of CVD. ${ }^{1}$ However, it is strongly believed that some of these cardiovascular-related deaths can be prevented by implementation of adequate treatment and preventive measures. ${ }^{2}$
Correspondence: Baishali M Amebgaonkar Merck and Co, Inc., I Merck Drive, Whitehouse Station, NJ 08889, USA Email baishali_ambegaonkar@merck.com 
In Lebanon and Jordan, CVD accounts for $45 \%$ and $40 \%$ of deaths, respectively. ${ }^{3,4}$ This high prevalence of CVD is likely associated with several known risk factors, including tobacco smoking, alcohol consumption, physical inactivity, and poor diet. These lifestyle choices can lead to several conditions that directly contribute to CVD risk (eg, diabetes mellitus, obesity, dyslipidemia, hypertension). ${ }^{5,6}$ In particular, the prevalences of obesity and tobacco smoking are very high in Lebanon and Jordan. Strikingly, the rates of obesity in Lebanon and Jordan are $27.4 \%$ and $30 \%$, respectively. ${ }^{3,4}$ In addition, according to the World Health Organization, the rates of tobacco use in these countries are among the highest in the world, ${ }^{7}$ with almost half of all males aged $\geq 15$ years being smokers. In addition, Lebanon has a very high rate of tobacco use among females (31\% of women aged $\geq 15$ years) as well as the highest prevalence of smoking among minors, ie, those aged 13-15 years (boys, 65.8\%; girls, 54.1\%). Thus, it is critical that Lebanon and Jordan implement preventative measures to combat these well-known CVD risk factors.

Although lifestyle changes are essential for combating CVD, it is also known that cardiovascular risk can be reduced by statin therapy. ${ }^{8,9}$ Research has shown that for every $1 \mathrm{mmol} / \mathrm{L}$ reduction in low-density lipoprotein cholesterol (LDL-C) level, there is a 23\% decrease in CVD risk. ${ }^{10-13}$ Moreover, it has been suggested that reduced high-density lipoprotein cholesterol (HDL-C) and elevated triglyceride levels might also contribute to CVD. ${ }^{14,15}$ Nevertheless, recent studies have indicated that patients undergoing statin treatment can experience persistent dyslipidemia, which can involve all three lipid irregularities (ie, raised LDL-C, decreased HDL-C, and elevated triglycerides). ${ }^{16-19}$ Therefore, the ongoing Dyslipidemia International Study (DYSIS) has systematically assessed the efficacy of statin therapy in patients from several countries around the world to better understand the risk factors associated with dyslipidemia and CVD. ${ }^{16,20-26}$

In the present analysis, which is part of DYSIS, we analyzed the prevalence of lipid abnormalities in patients receiving chronic statin therapy in Lebanon and Jordan. We also identified specific risk factors leading to dyslipidemia in these countries, contributing to our understanding of CVD risk. Notably, this information can promote the implementation of much needed programs for preventing and treating CVD in Lebanon and Jordan.

\section{Materials and methods Study design and patients}

This DYSIS in Lebanon and Jordan was an observational, cross-sectional, multicenter study conducted between
December 8, 2011 and April 30, 2012 at eight hospitals in Lebanon and five hospitals in Jordan. Data were collected using local language case report forms. Prior to the study, informed consent was obtained from all patients, and local ethical review committees approved the study protocol. A total of 617 patients comprising 325 men and 290 women (for two patients, sex was not documented) were enrolled based on the following criteria: age at least 45 years, treated with statins for at least 3 months, and at least one fasting blood lipid profile available while on statins (within the previous 6-12 months). We were not able to obtain a lipid profile before starting treatment for dyslipidemia.

\section{Data collection}

Patient demographic, lifestyle, and clinical characteristics were documented. In addition, their serum lipid levels (LDL-C, HDL-C, total cholesterol, and triglyceride) were determined based on their most recent blood tests (within 6-12 months). The lipid-lowering regimen used by each patient at the time of lipid measurement was also recorded. In particular, information was collected pertaining to type of statin, dose level, and other lipid-modifying therapies utilized. Potency of the various statins was normalized using a calculation that allows benchmarking against six different simvastatin dose levels $(5,10,20,40,80$, and $160 \mathrm{mg} /$ day), with potency scores ranging from 1 (5 mg/day simvastatin) to $6(160 \mathrm{mg}$ /day simvastatin $) .{ }^{27,28}$ The dose considered equivalent to $40 \mathrm{mg}$ of simvastatin was $20 \mathrm{mg}$ for atorvastatin, $160 \mathrm{mg}$ for fluvastatin, $4 \mathrm{mg}$ for pitavastatin, $80 \mathrm{mg}$ for lovastatin, $80 \mathrm{mg}$ for pravastatin, and $5 \mathrm{mg}$ for rosuvastatin.

\section{Cardiovascular risk classification}

Cardiovascular risk, LDL-C treatment goals, and abnormalities in HDL-C/triglyceride levels were classified based on 2011 European Society of Cardiology guidelines. ${ }^{29}$ Multivariate logistic regression analysis was used to analyze associations between baseline variables and dyslipidemia. The following variables were considered: age ( $\geq 70$ years), female sex, family history of premature coronary heart disease, current smoking, sedentary lifestyle, alcohol consumption ( $>2$ units/week), body mass index $\geq 30 \mathrm{~kg} / \mathrm{m}^{2}$, waist circumference ( $>102 \mathrm{~cm}$ in men, $>88 \mathrm{~cm}$ in women), hypertension, diabetes mellitus, ischemic heart disease, cerebrovascular disease, heart failure, peripheral artery disease, systolic/diastolic blood pressure $\geq 140 / 90 \mathrm{mmHg}$, equivalent simvastatin dose (20-40 versus 5-10 mg/day), and treatment with ezetimibe. 


\section{Statistical analysis}

The data were entered into a central database housed and managed at the Institut für Herzinfarktforschung, Ludwigshafen, Germany. During web-based entry, internal logic checks provided real-time quality control. Continuous variables were presented as means with standard deviations or medians with 25 th and 75 th percentiles (interquartile range). Categorical variables were reported as absolute numbers and percentages. Kernel density plots were used to examine distributions of total cholesterol, LDL-C, HDL-C, and triglyceride levels. Multiple logistic regression analyses with backward selection ( $\alpha=0.05)$ were used to identify variables that were independently associated with LDL-C, HDL-C, and triglyceride irregularities. Two-tailed statistical comparisons were used $(P<0.05$ was statistically significant), and patients lacking the appropriate lipid parameters were not included. The statistical analysis was performed using SAS version 9.1 (SAS Institute Inc., Cary, NC, USA).

\section{Results}

\section{Patient characteristics}

Patient characteristics, risk categories, and lipid parameters are presented in Table 1 . The study population ( $47 \%$ female) was predominantly of Arabic descent and had a mean age of 60.3 years. The rates of family history of premature coronary heart disease $(36.2 \%)$, hypertension $(72.9 \%)$, and diabetes mellitus $(51.8 \%)$ were found to be similar among men and women. However, men were more often cigarette smokers (33.5\% versus $22.8 \%$ of women) and showed almost twice the rate of CVD (47.1\%) relative to women (28\%). On the other hand, women displayed more metabolic syndrome (78.5\% versus $68.6 \%$ of men) and obesity ( $47 \%$ versus $38.8 \%$, respectively). Using the 2011 European Society of Cardiology criteria, $70 \%$ of the population $(76 \%$ men and $63.3 \%$ of women) were classified as very high risk for cardiovascular complications (defined as having CVD, diabetes mellitus, and/or a European Society of Cardiology Systematic Coronary Risk Evaluation ${ }^{29}[\mathrm{SCORE}]$ risk $\geq 10 \%$ ).

Table I Patient characteristics, risk categories, and lipid parameters (numbers included)

\begin{tabular}{|c|c|c|c|}
\hline & All patients $(n=6 \mid 7)$ & Men $(n=325)$ & Women $(n=290) *$ \\
\hline Age, years (mean $\pm S D)$ & $60.3 \pm 9.7$ & $60.0 \pm 9.8$ & $60.5 \pm 9.6$ \\
\hline Arabic (\%) & 92.7 & 93.2 & 92.1 \\
\hline Family history of premature CHD (\%) & 36.2 & 38.2 & 34.3 \\
\hline Current smoker (\%) & 28.5 & 33.5 & 22.8 \\
\hline Hypertension (\%) & 72.9 & 71.4 & 74.7 \\
\hline Systolic BP, mmHg (mean $\pm \mathrm{SD})$ & $130.4 \pm \mid 5.1$ & $130.3 \pm 14.6$ & $130.6 \pm 15.7$ \\
\hline Diastolic BP, mmHg (mean $\pm \mathrm{SD})$ & $78.7 \pm 9.3$ & $78.6 \pm 9.3$ & $78.8 \pm 9.4$ \\
\hline Waist circumference, $\mathrm{cm}$ (mean $\pm \mathrm{SD})$ & $101.7 \pm 12.7$ & $103.9 \pm 12.4$ & $99.3 \pm 12.7$ \\
\hline $\mathrm{BMI}, \mathrm{kg} / \mathrm{m}^{2}($ mean $\pm \mathrm{SD})$ & $29.7 \pm 5.4$ & $29.3 \pm 4.7$ & $30.2 \pm 5.9$ \\
\hline $\mathrm{BMI} \geq 30 \mathrm{~kg} / \mathrm{m}^{2}(\%)$ & 42.6 & 38.8 & 47.0 \\
\hline CVD (\%) & 38.0 & 47.1 & 28.0 \\
\hline Diabetes mellitus (\%) & 51.8 & 52.0 & 51.6 \\
\hline Type I (\%) & 4.1 & 4.2 & 4.1 \\
\hline Type 2 (\%) & 95.9 & 95.9 & 96.0 \\
\hline Metabolic syndrome (IDF, \%) & 73.2 & 68.6 & 78.5 \\
\hline \multicolumn{4}{|l|}{ 20I I ESC risk level } \\
\hline Very high-risk patient (\%) & 70.0 & 76.0 & 63.3 \\
\hline High-risk patient (\%) & 6.0 & 7.1 & 4.8 \\
\hline Moderate-risk patient (\%) & 16.7 & 16.6 & 17.0 \\
\hline Low-risk patient (\%) & 7.3 & 0.3 & 14.9 \\
\hline \multicolumn{4}{|l|}{ Lipids } \\
\hline LDL-C, mmol/L (mean \pm SD) & $2.5 \pm 1.1$ & $2.5 \pm 1.1$ & $2.5 \pm 1.1$ \\
\hline HDL-C, mmol/L (mean \pm SD) & $1.2 \pm 0.4$ & $\mathrm{I} . \mathrm{I} \pm 0.4$ & $\mathrm{I} .3 \pm 0.4$ \\
\hline Total cholesterol, mmol/L (mean \pm SD) & $4.4 \pm 1.4$ & $4.2 \pm 1.5$ & $4.5 \pm 1.3$ \\
\hline Triglycerides, mmol/L (median [IQR]) & $\mathrm{I} .5(\mathrm{I} .0-2.2)$ & $1.4(1.0-2.1)$ & $1.6(I .1-2.4)$ \\
\hline Blood glucose, mmol/L & $5.6(4.6-7.3)$ & $5.7(4.8-7.4)$ & $5.4(4.5-7.1)$ \\
\hline Fasting plasma glucose, $\mathrm{mmol} / \mathrm{L}$ & $7.1(6.3-8.2)$ & $7.1(6.4-8.1)$ & $7.0(6.3-8.5)$ \\
\hline $\mathrm{HbA}_{\mathrm{Ic}}(\%)$ in diabetic patients & $7.9(6.8-8.7)$ & $7.9(6.9-8.6)$ & $7.8(6.8-8.7)$ \\
\hline
\end{tabular}

Notes: *For two patients information on sex was not available. Figures in brackets are median with IQR.

Abbreviations: CHD, coronary heart disease; BP, blood pressure; BMI, body mass index; CVD, cardiovascular disease; DM, diabetes mellitus; IDF, International Diabetes Federation; LDL-C, low-density lipoprotein cholesterol; HDL-C, high-density lipoprotein cholesterol; IQR, interquartile range; HbA deviation; ESC, European Society of Cardiology. 


\section{Lipid-modifying regimens and statin potency}

Patients had been treated with various lipid-lowering therapies. The most commonly prescribed statin was atorvastatin (44.6\%), followed by simvastatin (27.7\%), rosuvastatin (21.2\%), fluvastatin $(3.3 \%)$, pravastatin $(3 \%)$, and lovastatin $(0.2 \%)$. In addition, other lipid-lowering agents had been used by $14.8 \%$ of the patients, including ezetimibe (6.3\%), fibrate (9.1\%), and nicotinic acid $(0.2 \%)$. Moreover, approximately half of the population was treated with a statin dose potency of 4 (very high-risk patients [45.6\%] and not very high-risk patients [45.5\%]). The second most frequently used dose potency was 3 (31.7\% and $33.7 \%$ for very high-risk patients and not very high-risk patients, respectively, Figure 1).

\section{Lipid abnormalities}

Data regarding lipid abnormality frequencies, including subanalyses based on CVD risk level, are shown in Tables 2 and 3. Among all patients with a total lipid profile available $(\mathrm{n}=539$, Table 3), 56.2\% had LDL-C levels not at goal; $45.3 \%$ had low HDL-C levels, and $42.1 \%$ had elevated triglycerides. Similarly, the most prevalent lipid disorder in very high-risk patients $(\mathrm{n}=367)$ was above target LDL-C levels $(67.0 \%)$, followed by low HDL-C levels (49.0\%) and elevated triglycerides $(42.2 \%)$. On the other hand, although high-risk patients $(\mathrm{n}=36)$ most frequently showed LDL-C levels above goal (61.1\%), this subgroup displayed slightly more elevated triglycerides (38.9\%) than low HDL-C (36.1\%). In moderaterisk patients $(\mathrm{n}=96)$, the rates of these three lipid profiles were more evenly distributed (above target LDL-C, 36.5\%, low HDL-C, 43.8\%; elevated triglycerides, 43.8\%). Notably, these frequencies were similar to what was observed when analyzing the entire study population.

A subanalysis of lipid abnormalities in very high-risk individuals having a total lipid profile was also performed, stratifying patients based on the following categories: CVD with diabetes mellitus, CVD only, diabetes mellitus only, and a SCORE risk of $\geq 10 \%$ (Table 3). Among those with both CVD and diabetes mellitus, $68.5 \%$ displayed off-target LDL-C levels ( $\geq 1.8 \mathrm{mmol} / \mathrm{L}$ ), $55.9 \%$ showed low HDL-C levels, and $49.5 \%$ had elevated triglyceride levels. Those having only diabetes mellitus displayed a similar trend, but with slightly lower rates (above target LDL-C, 65.1\%; low HDL-C, 51.0\%; elevated triglycerides, 40.9\%). Although patients with CVD displayed a similar prevalence of high LDL-C (67.4\%), these individuals had the lowest rates of low HDL-C (39.1\%) and elevated triglycerides (32.6\%). Strikingly, the SCORE risk of $\geq 10 \%$ group showed the highest proportion of patients with LDL-C not at target (73.3\%) and elevated triglycerides $(60.0 \%)$. In addition, we conducted this same analysis in all high-risk patients, irrespective of total lipid profile, and observed similar results. Taken together, we found that LDL-C not at goal was the most common lipid irregularity observed in all of the high-risk categories.

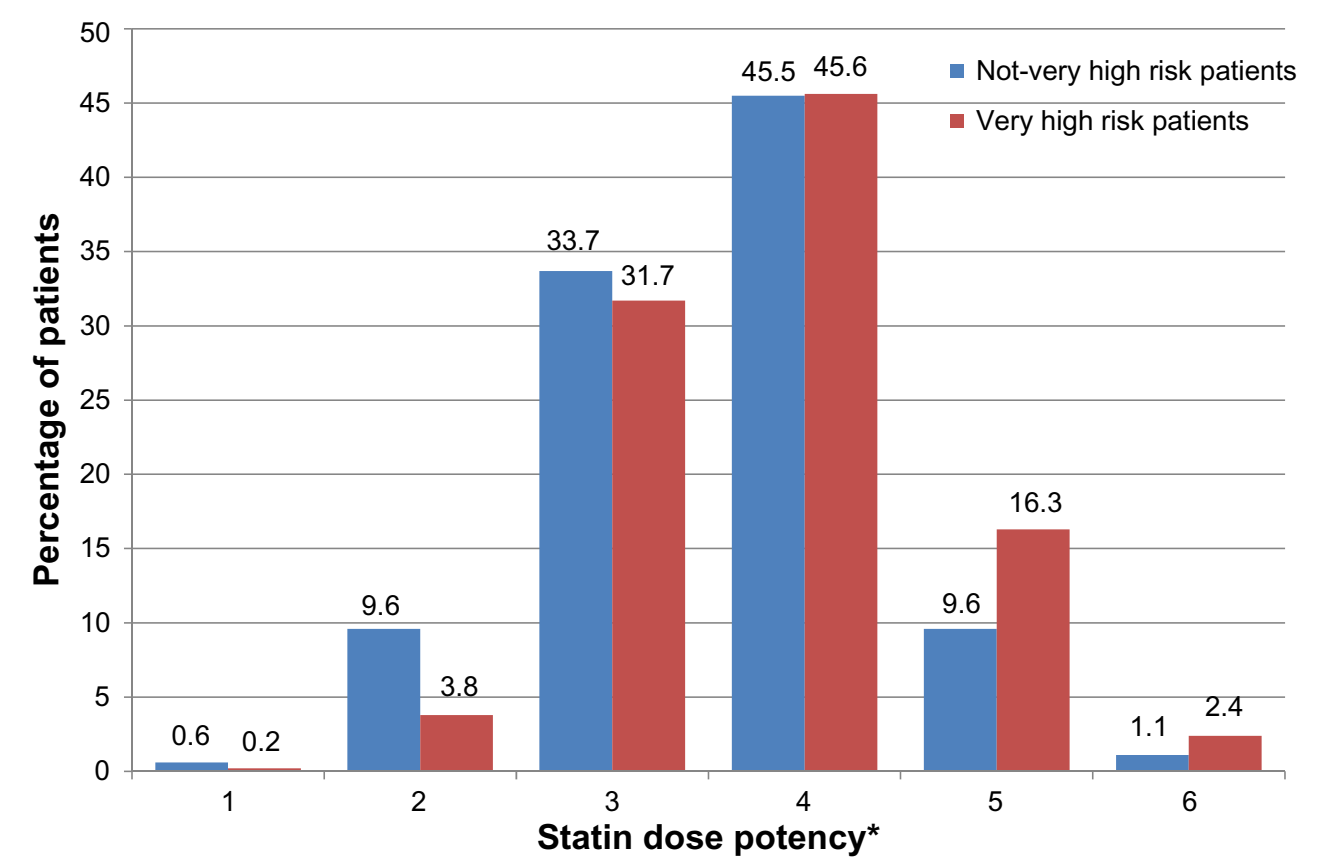

Figure I Statin dose potency according to patient risk status.

Notes: *Statin dose potency I is equivalent to simvastatin $5 \mathrm{mg} /$ day, potency 2 is equivalent to simvastatin $10 \mathrm{mg} /$ day, potency 3 is equivalent to simvastatin $20 \mathrm{mg} /$ day, potency 4 is equivalent to simvastatin $40 \mathrm{mg} /$ day, potency 5 is equivalent to simvastatin $80 \mathrm{mg} /$ day, and potency 6 is equivalent to simvastatin $\geq 160 \mathrm{mg} /$ day. 
Table 2 Lipid abnormalities according to 201 I European Society of Cardiology guidelines

\begin{tabular}{|c|c|c|c|c|c|}
\hline Patients with total lipid profile & $\begin{array}{l}\text { All patients } \\
(n=539)\end{array}$ & $\begin{array}{l}\text { Very high risk* } \\
(n=367)\end{array}$ & $\begin{array}{l}\text { High risk } \\
(n=36)\end{array}$ & $\begin{array}{l}\text { Moderate risk } \\
(\mathrm{n}=96)\end{array}$ & $\begin{array}{l}\text { Low risk } \\
(n=40)\end{array}$ \\
\hline LDL-C not at target, $\%^{\dagger}$ & 56.2 & 67.0 & 61.1 & 36.5 & $\Delta$ \\
\hline Low HDL-C $(<1.0[\mathrm{men}] /<\mathrm{I} .2[$ women] $\mathrm{mmol} / \mathrm{L}), \%$ & 45.3 & 49.0 & 36.1 & 43.8 & 22.5 \\
\hline Elevated TG (>I.7 mmol/L), \% & 42.1 & 42.2 & 38.9 & 43.8 & 40.0 \\
\hline All patients & $(n=616)$ & $(n=43 I)$ & $(n=37)$ & $(n=103)$ & $(n=45)$ \\
\hline LDL-C not at target, $\%^{\dagger}$ & 55.9 & 67.2 & 61.1 & 36.5 & $\Delta$ \\
\hline Low HDL-C $\left(<\mathrm{I} .0[\mathrm{men}] /<\mathrm{I} .2[\right.$ women] $\mathrm{mmol} / \mathrm{L}), \%^{\ddagger}$ & 48.3 & 52.8 & 37.8 & 44.7 & 23.3 \\
\hline Elevated TG $(>1.7 \mathrm{mmol} / \mathrm{L}), \% \S$ & 41.3 & 40.8 & 37.8 & 43.7 & 43.2 \\
\hline
\end{tabular}

Notes: *Very high risk $=$ CVD, diabetes, and/or SCORE risk $\geq 10 \%$ (chronic kidney disease was not documented in DYSIS); ${ }^{2} L D L-C \geq 3.0$ mmol/L in patients with SCORE risk $1 \%-4 \%$, LDL $\geq 2.5 \mathrm{mmol} / \mathrm{L}$ in patients with SCORE risk $5 \%-9 \%$, LDL-C $\geq 1.8 \mathrm{mmol} / \mathrm{L}$ in patients with CVD, diabetes, and/or SCORE risk $\geq 10 \%$; data on 546 patients were available for "all patients"; ${ }^{\ddagger}$ data on 600 patients were available; ${ }^{\S}$ data on 60 I patients were available; ${ }^{\Delta}$ in the 20 I I ESC guidelines, no LDL-C goal was specified for the low-risk group; low HDL-C was defined as $<1.0 \mathrm{mmol} / \mathrm{L}$ for men and $<1.2 \mathrm{mmol} / \mathrm{L}$ for women; elevated TG was defined as $>1.7 \mathrm{mmol} / \mathrm{L}$.

Abbreviations: CVD, cardiovascular disease; LDL-C, low-density lipoprotein cholesterol; HDL-C, high-density lipoprotein cholesterol; TG, triglycerides; DYSIS, Dyslipidemia International Study; ESC, European Society of Cardiology; SCORE, Systematic Coronary Risk Evaluation.

Additionally, we used kernel density curves to demonstrate that the very high-risk group had lower overall LDL-C levels than not very high-risk patients (European Society of Cardiology guidelines for LDL-C goals indicated as superimposed vertical lines, Figure 2). We also used these curves to demonstrate that women maintained higher overall HDL-C levels in the not very high-risk group in comparison with men, whereas very high-risk women and men displayed similar HDL-C levels. Moreover, similar triglyceride levels were observed for the two risk groups.

\section{Distribution of lipid abnormalities}

The distributions of single and multiple combined lipid abnormalities are shown in Figure 3A-F. We first analyzed the distributions of not very high-risk patients who had at least one abnormality (Figure 3A). We observed that $57.2 \%$ had only one lipid abnormality, 29.9\% had two lipid abnormalities, and the remaining $12.9 \%$ had all three lipid abnormalities. For these not very high-risk patients, elevated triglycerides represented the largest single abnormality (21.8\%), accounting for approximately $40 \%$ of all not very high-risk patients with one abnormality. In contrast, the majority (59.6\%) of very high-risk patients with at least one abnormality (Figure 3B) had two or more lipid abnormalities (one, $40.4 \%$; two, 42.6\%; three, 17\%). Moreover, high LDL-C was the most frequent single abnormality observed for very high-risk patients $(21.9 \%)$, accounting for $>50 \%$ of patients with one abnormality in this subgroup. Also in this population, low HDL-C and elevated triglycerides were the least likely to coexist in cases involving two simultaneous lipid irregularities (15.7\% of patients with double abnormalities).

In Figure $3 \mathrm{C}$ and $\mathrm{D}$ we present distributions similar to those described above; however, this time we include information for not very high-risk patients and high-risk patients with no lipid abnormalities. Among the not very high-risk patients, $27.9 \%$ had no abnormalities, whereas $10.4 \%$ of very high-risk individuals showed no abnormalities. Overall, we observed that although the proportions of lipid abnormalities were slightly less in distribution plots that included those with no lipid abnormalities, the overall trend of the results remained unchanged.

The lipid abnormality distribution for all patients with at least one irregularity is shown in Figure 3E. We observed that $45 \%$ of statin-treated patients in this group harbored a

Table 3 Lipid abnormalities according to 201 I European Society of Cardiology guidelines in very high-risk patients

\begin{tabular}{|c|c|c|c|c|}
\hline Patients with total lipid profile & $\begin{array}{l}\text { CVD + DM } \\
(n=I I I)\end{array}$ & $\begin{array}{l}\text { CVD (no DM) } \\
(n=92)\end{array}$ & $\begin{array}{l}\text { DM (no CVD) } \\
(n=\mid 49)\end{array}$ & $\begin{array}{l}\text { SCORE } \geq 10 \% \\
(n=15)\end{array}$ \\
\hline LDL-C $\geq 1.8 \mathrm{mmol} / \mathrm{L}$ and LDL-reduction $<50 \%$, $\%$ & 68.5 & 67.4 & 65.1 & 73.3 \\
\hline Low HDL-C $(<1.0[\mathrm{men}] /<1.2$ [women] mmol/L), \% & 55.9 & 39.1 & 51.0 & 40.0 \\
\hline Elevated TG (>I.7 mmol/L), \% & 49.5 & 32.6 & 40.9 & 60.0 \\
\hline All patients & $(n=137)$ & $(n=97)$ & $(n=181)$ & $(n=15)$ \\
\hline LDL-C $\geq 1.8 \mathrm{mmol} / \mathrm{L}$ and LDL-reduction $<50 \%, \% *$ & 68.8 & 67.4 & 65.1 & 73.3 \\
\hline Low HDL-C $\left(<\mathrm{I} .0[\mathrm{men}] /<\mathrm{I} .2\left[\right.\right.$ women] mmol/L), \% ${ }^{\dagger}$ & 59.1 & 40.2 & 56.2 & 40.0 \\
\hline Elevated TG $(>1.7 \mathrm{mmol} / \mathrm{L}), \%^{\ddagger}$ & 46.8 & 30.9 & 40.4 & 60.0 \\
\hline
\end{tabular}

Notes: *Data on 368 patients were available; †data on 417 patients were available; $¥$ data on 416 patients were available.

Abbreviations: CVD, cardiovascular disease; LDL-C, low-density lipoprotein cholesterol; HDL-C, high-density lipoprotein cholesterol; TG, triglycerides; DM, diabetes mellitus. 


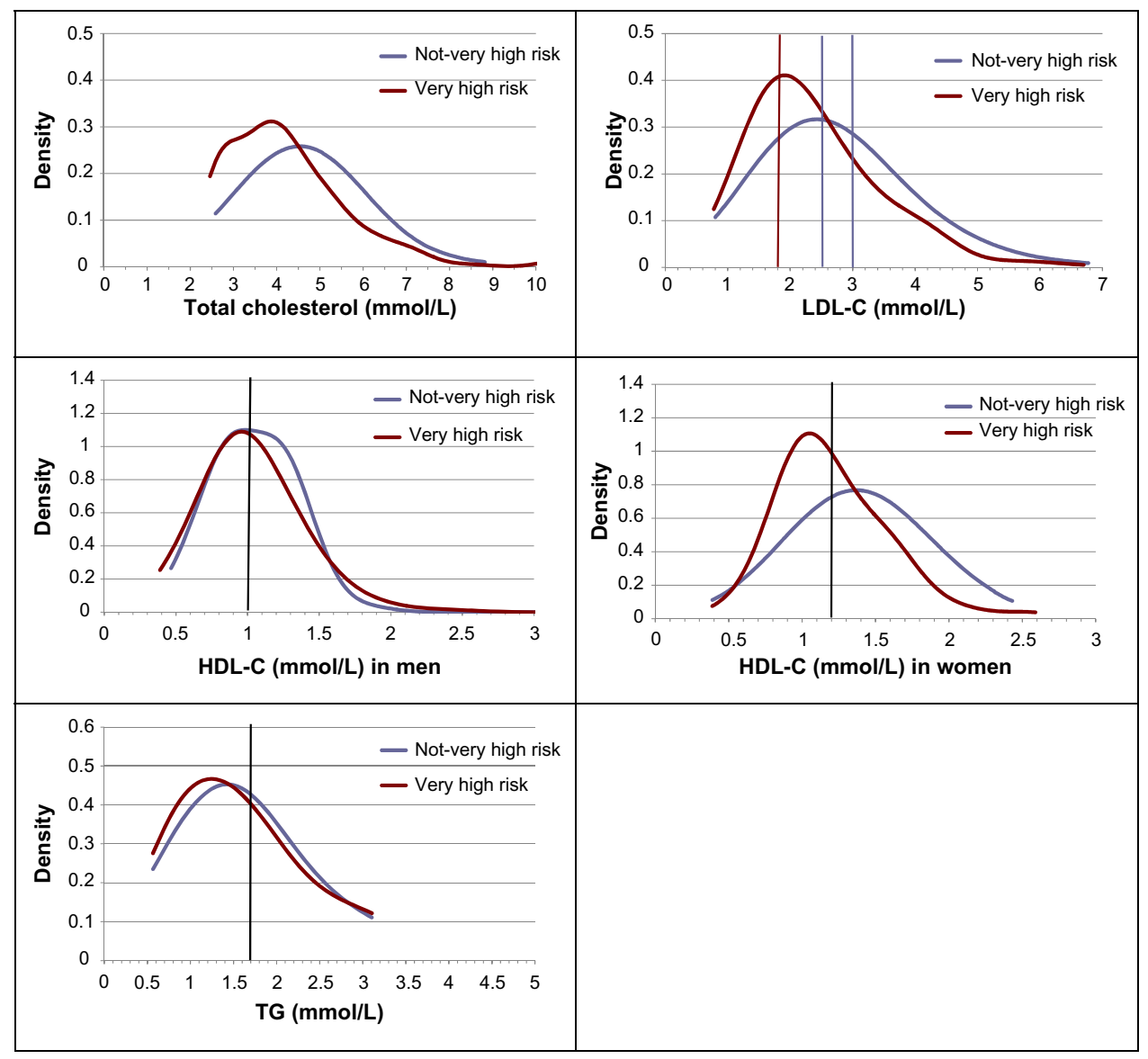

Figure 2 Kernel density curves of lipids. Vertical lines mark the cut point of the 20I I European Society of Cardiology guidelines. Abbreviations: HDL-C, high density lipoprotein cholesterol; LDL-C, low density lipoprotein cholesterol; TG, triglycerides.

single abnormality, 39\% had two abnormalities, and $15.9 \%$ all three lipid abnormalities. The most frequent single irregularity was high LDL-C (20.5\%), accounting for approximately half of all patients with one lipid abnormality. Also, low HDL-C and elevated triglycerides were less likely to coexist in cases involving two lipid irregularities (22\% of patients with double abnormalities). Finally, we found that adding patients with no lipid abnormalities to this distribution led to a slight decrease in the percentages but did not alter our overall findings (Figure 3F).

\section{Variables having an independent association with dyslipidemia}

We identified several variables independently associated with abnormal LDL-C, HDL-C, and triglyceride levels in Lebanon and Jordan (Table 4). LDL-C level not at goal was correlated with current tobacco smoking, alcohol consumption ( $>2$ units/week), diabetes mellitus, and ischemic heart disease. Variables associated with low HDL-C levels in multivariate logistic regression analysis included sex (female), current tobacco smoking, and diabetes mellitus.
Finally, elevated triglyceride levels were found to be associated with waist circumference. Notably, the strongest independent indicators for the presence of all three of the lipid irregularities were tobacco use and diabetes mellitus.

\section{Discussion}

In this latest DYSIS investigation, we found that $>70 \%$ of statin-treated patients in Lebanon and Jordan could be classified as being at very high risk for cardiovascular complications. Even with ongoing statin therapy, goal LDL-C levels were not attained in over half of all patients, including approximately $67 \%$ of those considered to be at very high risk. Moreover, low HDL-C and elevated triglycerides were observed in $48 \%$ and $41 \%$ of all statin-treated patients, respectively. We detected at least one lipid irregularity in three quarters of the study population, with $11.7 \%$ simultaneously displaying all three of the lipid abnormalities (ie, high LDL-C, low HDL-C, and elevated triglycerides).

In Lebanon and Jordan, we identified diabetes mellitus and tobacco smoking as the patient characteristics most strongly associated with dyslipidemia involving all three lipid 
abnormalities in statin-treated patients. Strikingly, over half of our study population had type 2 diabetes, and the rates of tobacco use in Lebanon, in particular, and Jordan are among some of the highest in the world. ${ }^{7}$ Also, these two countries have an extremely high prevalence of obesity (approximately $30 \%$ each), ${ }^{3,4}$ which along with tobacco smoking is strongly linked with the development of type 2 diabetes. ${ }^{30,31}$ Thus, the high prevalence of diabetes mellitus observed in this population may not be surprising.

Based on our findings, it appears that obesity and smoking should be robustly targeted in preventative and therapeutic interventions in Lebanon and Jordan. Specifically, emphasis should be placed on the development of social programs to discourage tobacco use among minors in Lebanon, where statistics regarding youth smoking are alarming. ${ }^{3}$ In addition, approximately one third of women in Lebanon use tobacco, compared with $6 \%$ in Jordan, ${ }^{3}$ representing another demographic that would benefit heavily from control initiatives. However, it appears that implementing such tobacco prevention programs may be a challenge in Lebanon, given that a recent ban on smoking in public areas passed by the Lebanese government in September 2012 has been largely ignored..$^{32}$

In addition to identifying patient characteristics associated with dyslipidemia in statin-treated patients, DYSIS has highlighted the inadequacy of current lipid-lowering treatment strategies in Lebanon and Jordan. The results obtained here are similar to those found in other recent DYSIS studies conducted in various regions of the world..$^{16,20-26}$ In addition, other researchers analyzing the efficacy of lipid-lowering therapies have supported these conclusions. ${ }^{17,19}$ Collectively, these studies suggest that novel therapeutic approaches need to be developed or existing treatment strategies improved.
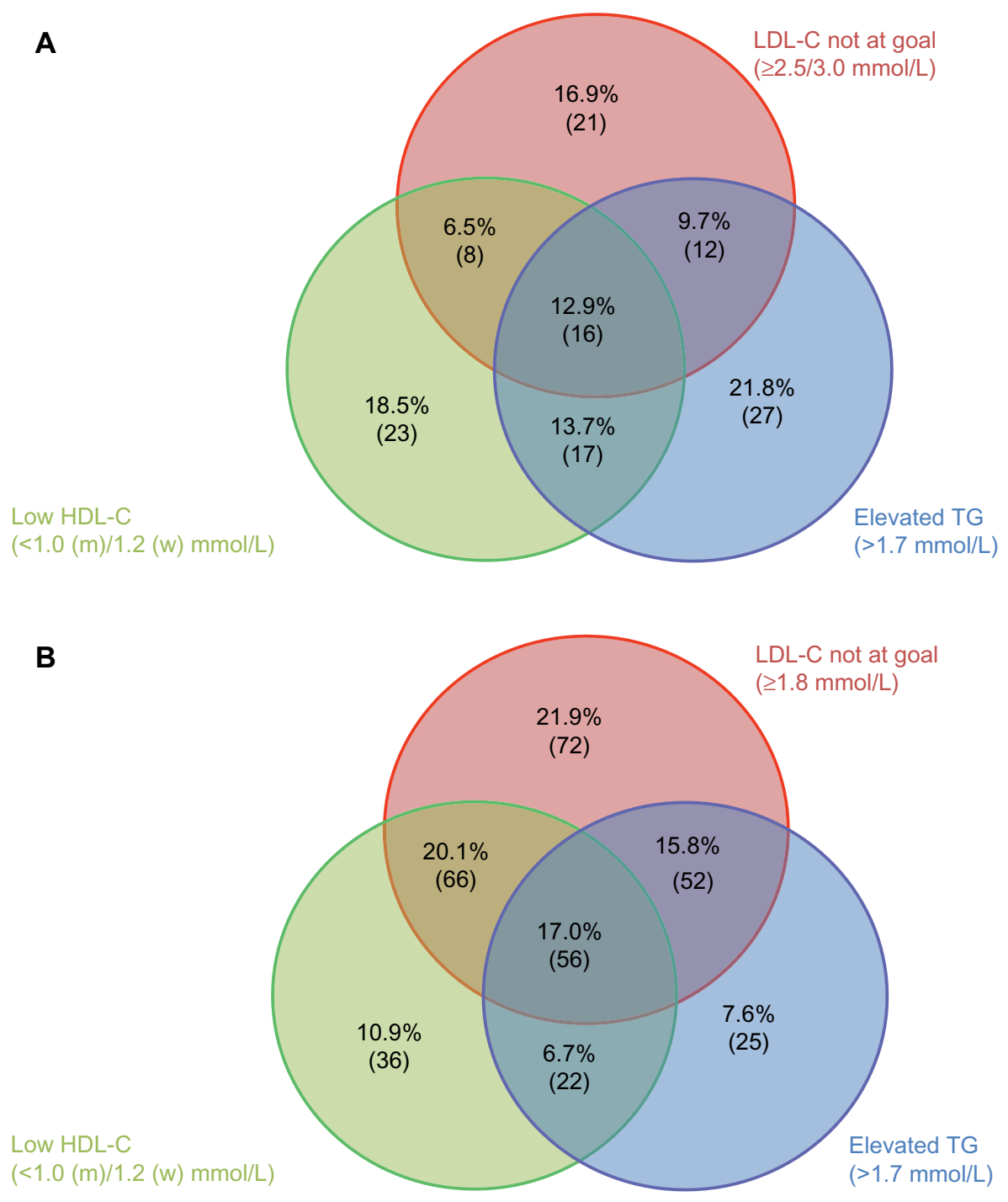

Figure 3 (Continued) 


\section{C}
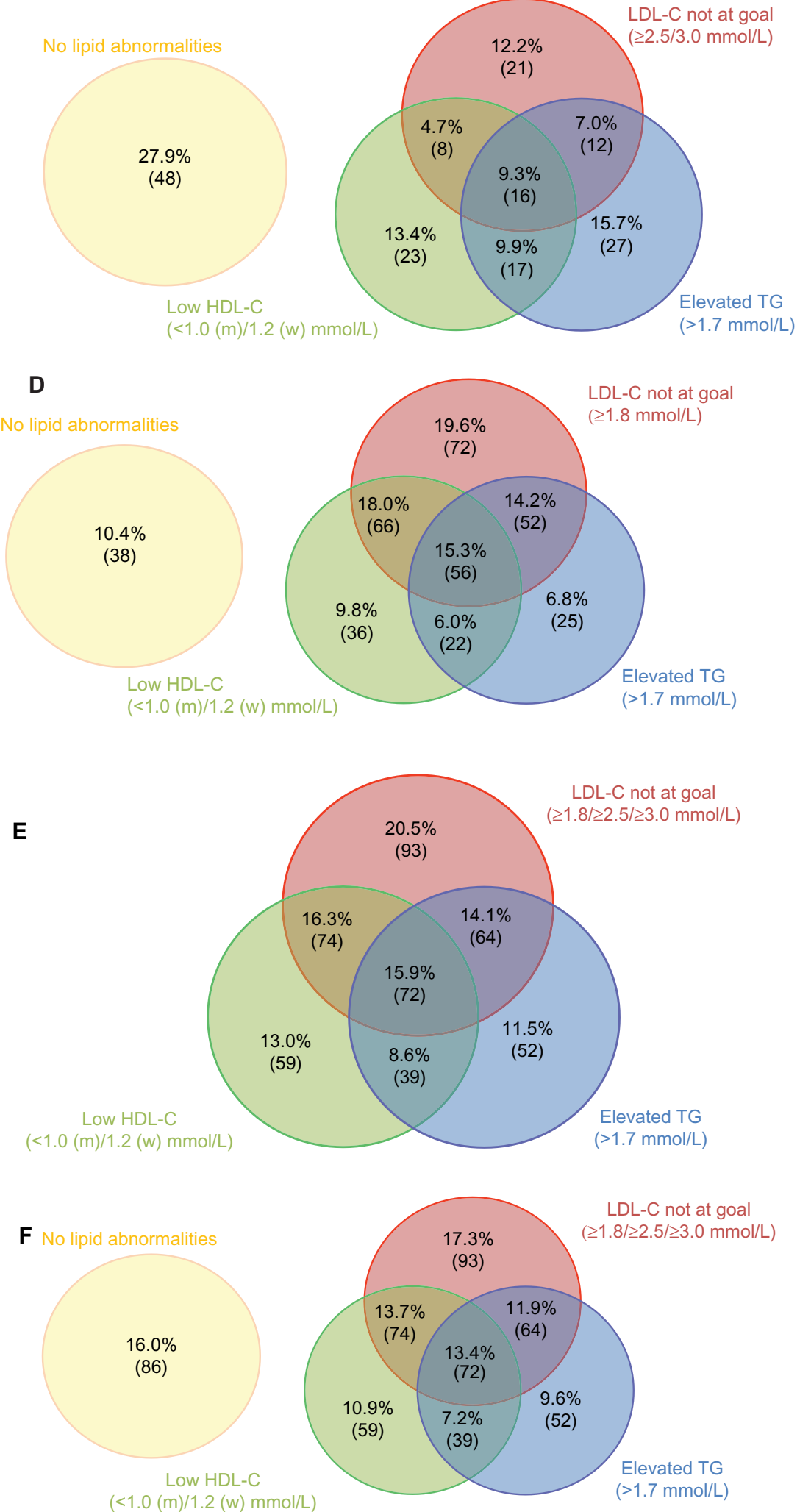

Figure 3 (A and B) Distribution of single and multiple combined lipid abnormalities. (A) Not very high-risk patients (ESC 20I I, SCORE < I0\%) with at least one lipid abnormality. (B) Very high-risk patients (ESC 20II, cardiovascular disease, diabetes, and/or ESC SCORE $\geq 10 \%$ ) with at least one lipid abnormality. (C and D) Distribution of single and multiple combined lipid abnormalities. (C) Not very high-risk patients (ESC 20II, SCORE <10\%). (D) Very high-risk patients (ESC 20II, cardiovascular disease, diabetes, and/or ESCSCORE $\geq 10 \%$ ). (E and F) Distribution of single and multiple combined lipid abnormalities. (E) Patients with at least one lipid abnormality. (F) Patients with total lipid profile. Abbreviations: LDL-C, low-density lipoprotein cholesterol; HDL-C, high-density lipoprotein cholesterol; TG, triglycerides; ESC, European Society of Cardiology; SCORE, Systematic Coronary Risk Evaluation; m, men; w, women. 
Table 4 Factors independently associated with LDL-C, HDL-C, and triglyceride abnormalities: results of multivariable logistic regression (odds ratio, 95\% confidence interval)

\begin{tabular}{|c|c|c|c|c|}
\hline & $\begin{array}{l}\text { LDL-C not at target* } \\
(\geq 1.8 / 2.5 / 3.0 \mathrm{mmol} / \mathrm{L})\end{array}$ & $\begin{array}{l}\text { Low HDL-C* } \\
(<\mathrm{I.0}(\mathrm{m}) / \mathrm{I} .2(\mathrm{w}) \\
\mathrm{mmol} / \mathrm{L})\end{array}$ & $\begin{array}{l}\text { Elevated TG* } \\
(>1.7 \mathrm{mmol} / \mathrm{L})\end{array}$ & $\begin{array}{l}\text { LDL-C not at target } \\
\text { and low HDL-C and } \\
\text { elevated TG* }\end{array}$ \\
\hline Female & NS & $0.66(0.46-0.95)$ & NS & NS \\
\hline Current smoker & $1.96(1.25-3.08)$ & $2.02(1.34-3.04)$ & NS & $3.09(1.76-5.44)$ \\
\hline Alcohol consumption $>2$ units/week & $0.12(0.03-0.57)$ & NS & NS & NS \\
\hline$W C>102(m) />88(w) c m$ & NS & NS & $1.48(1.01-2.16)$ & NS \\
\hline Diabetes mellitus & $2.53(1.70-3.77)$ & $2.38(1.65-3.44)$ & NS & $1.78(1.00-3.17)$ \\
\hline Ischemic heart disease & $2.26(1.45-3.53)$ & NS & NS & NS \\
\hline
\end{tabular}

Notes: *Models contained the following variables: age, sex, first grade family history of premature cardiovascular disease, current smoker, sedentary lifestyle, alcohol consumption $>2$ units/week, BMI $\geq 30 \mathrm{~kg} / \mathrm{m}^{2}$ (obesity), waist circumference $>102 \mathrm{~cm}$ in men/ $>88 \mathrm{~cm}$ in women, hypertension, diabetes mellitus, ischemic heart disease, cerebrovascular disease, heart failure, peripheral artery disease, $\mathrm{BP} \geq 140 / 90 \mathrm{mmHg}$ (systolic/diastolic), $20-40$ versus $10 \mathrm{mg} /$ day simvastatin equivalent, $\geq 80$ versus $10 \mathrm{mg} /$ day simvastatin equivalent, ezetimibe. Backward selection $(\alpha=0.05)$ was done.

Abbreviations: BMI, body mass index; m, men; w, women; BP, blood pressure; NS, not significant ( $P>0.05)$; LDL-C, low-density lipoprotein cholesterol; HDL-C, highdensity lipoprotein cholesterol; TG, triglycerides; WC, waist circumference; BP, blood pressure.

In this regard, it has been suggested that high doses of statins or combination therapies could be utilized to achieve LDL-C targets in high-risk patients. ${ }^{33-35}$ On the other hand, attempts to modify low HDL-C and high triglyceride levels using drugs such as fibrates and niacin have not resulted in a reduction of risk, as suggested by their documented association with increased cardiovascular risk. ${ }^{36-38}$

This DYSIS study had several limitations. Data for this investigation were collected at a single point in time, so did not permit analysis of the effects of statins over time or longterm cardiovascular risk. In addition, inclusion in the study was restricted to subjects receiving statin treatment, potentially creating bias in our results. Also, serum lipid levels were analyzed by local laboratories prior to the start of this study, which may have introduced variation in the patient data used in determining rates of dyslipidemia. Moreover, it is possible that patients' treatment regimens changed since the time when the original lipid measurements were obtained. Finally, we were not able to assess compliance/adherence issues, which might have contributed to the present results. However, despite these potential limitations, this study of dyslipidemia in Lebanon and Jordan has yielded fundamental information about the factors contributing to CVD risk in statin-treated patients.

\section{Conclusion}

DYSIS in Lebanon and Jordan has supported recent findings that suggest the inadequacy of current statin therapy protocols. Half of all statin-treated patients in Lebanon and Jordan did not meet target lipid levels and almost three quarters were at very high-risk for CVD. Our findings support the notion that novel dyslipidemia treatment strategies need to be considered. Also, it is essential that social programs aimed at lifestyle modification be initiated in Lebanon and Jordan, with special emphasis on tobacco use, diet, and physical activity. In particular, initiatives aimed at preventing smoking in youth and women are vital in Lebanon for combating CVD.

\section{Acknowledgments}

The authors would like to thank Dr Steffen Schneider, Stiftung Institut für Herzinfarktforschung, Ludwigshafen, Germany, for performing the statistical analyses, Dr Myrga Zankel (MSD International) for general support of the study, and Dr Lori D Bash (Merck and Co, Inc.) for critical content review. They are indebted to all investigators in Lebanon and Jordan and to the patients who participated in DYSIS.

\section{Author contributions}

BMAmbegaonkar and $\mathrm{P}$ Brudi contributed to the study concept and design. ST Azar, HA Hantash, S Jambart, MM El-Zaheri, R Rachoin, A Chalfoun, L Lahoud, O Okkeh, and P Bramlage contributed to data acquisition and interpretation of the study. P Bramlage drafted the manuscript and all other authors revised the article for important intellectual content. All authors read and approved the final manuscript to be published.

\section{Disclosure}

ST Azar, HA Hantash, S Jambart, MM El-Zaheri, R Rachoin, $\mathrm{O}$ Okkeh, and $\mathrm{P}$ Bramlage have received consultancy fees or research funds from Merck and Co, Ltd. A Chalfoun, L Lahoud, P Brudi, and BMAmbegaonkar are employees of the sponsors. This study was funded by Merck and Co, Inc. (Whitehouse Station, NJ, USA) and Merck Sharp and Dohme Levant (Beirut, Lebanon).

\section{References}

1. World Health Organization. Cardiovascular diseases (CVDs) Fact sheet no 317. 2012. Available from: http://www.who.int/mediacentre/ factsheets/fs317/en/index.html. Accessed February 11, 2014. 
2. World Health Organization in collaboration with the World Heart Federation and the World Stroke Organization. Global atlas on cardiovascular disease prevention and control - policies, strategies and interventions. 2011. Available from: http://www.who.int/cardiovascular_ diseases/publications/atlas_cvd/en/. Accessed February 11, 2014.

3. World Health Organization. NCD country profiles - Lebanon. 2011. Available from: http://www.who.int/nmh/countries/lbn_en.pdf. Accessed February 11, 2014.

4. World Health Organization. NCD country profiles - Jordan. 2011. Available from: http://www.who.int/nmh/countries/jor_en.pdf. Accessed February 11, 2014.

5. Gaziano TA, Bitton A, Anand S, Abrahams-Gessel S, Murphy A. Growing epidemic of coronary heart disease in low- and middle-income countries. Curr Probl Cardiol. 2010;35(2):72-115.

6. Gersh BJ, Sliwa K, Mayosi BM, Yusuf S. Novel therapeutic concepts: the epidemic of cardiovascular disease in the developing world: global implications. Eur Heart J. 2010;31(6):642-648.

7. World Health Organization. Global situations and trends: prevalence of tobacco use among adults and adolescents (interactive map). 2012. Available from: http://www.who.int/gho/tobacco/use/en/. Accessed February 11, 2014.

8. Taylor F, Ward K, Moore TH, et al. Statins for the primary prevention of cardiovascular disease. Cochrane Database Syst Rev. 2011;1:CD004816.

9. Zhou Q, Liao JK. Statins and cardiovascular diseases: from cholesterol lowering to pleiotropy. Curr Pharm Des. 2009;15(5):467-478.

10. Baigent C, Keech A, Kearney PM, et al. Efficacy and safety of cholesterol-lowering treatment: prospective meta-analysis of data from 90,056 participants in 14 randomised trials of statins. Lancet. 2005;366(9493):1267-1278.

11. Deedwania P, Barter P, Carmena R, et al. Reduction of low-density lipoprotein cholesterol in patients with coronary heart disease and metabolic syndrome: analysis of the Treating to New Targets study. Lancet. 2006;368(9539):919-928.

12. Kearney PM, Blackwell L, Collins R, et al. Efficacy of cholesterollowering therapy in 18,686 people with diabetes in 14 randomised trials of statins: a meta-analysis. Lancet. 2008;371(9607):117-125.

13. Wilt TJ, Bloomfield HE, MacDonald R, et al. Effectiveness of statin therapy in adults with coronary heart disease. Arch Intern Med. 2004;164(13):1427-1436.

14. Cziraky MJ, Watson KE, Talbert RL. Targeting low HDL-cholesterol to decrease residual cardiovascular risk in the managed care setting. J Manag Care Pharm. 2008;14(Suppl 8):S3-S28.

15. Nesto RW. Beyond low-density lipoprotein: addressing the atherogenic lipid triad in type 2 diabetes mellitus and the metabolic syndrome. Am J Cardiovasc Drugs. 2005;5(6):379-387.

16. Gitt AK, Drexel H, Feely J, et al. Persistent lipid abnormalities in statintreated patients and predictors of LDL-cholesterol goal achievement in clinical practice in Europe and Canada. Eur J Prev Cardiol. 2012;19(2): 221-230.

17. Kotseva K, Stagmo M, De Bacquer D, De Backer G, Wood D. Treatment potential for cholesterol management in patients with coronary heart disease in 15 European countries: findings from the EUROASPIRE II survey. Atherosclerosis. 2008;197(2):710-717.

18. Leiter LA, Lundman P, da Silva PM, Drexel H, Junger C, Gitt AK. Persistent lipid abnormalities in statin-treated patients with diabetes mellitus in Europe and Canada: results of the Dyslipidaemia International Study. Diabet Med. 2011;28(11):1343-1351.

19. Sudano I, Hess L, Noll G, Arnet D. Persistent dyslipidemia in statintreated patients: the focus on comprehensive lipid management survey in Swiss patients. Swiss Med Wkly. 2011;141:w13200.
20. Strang AC, Kaasjager HA, Basart DC, Stroes ES. Prevalence of dyslipidaemia in patients treated with lipid-modifying drugs in The Netherlands. Part of the Dyslipidaemia International Survey. Neth $J$ Med. 2010;68(4):168-174.

21. Liberopoulos E, Vlasserou F, Mitrogianni Z, Papageorgantas I, Elisaf M. Prevalence and risk distribution of residual dyslipidemia in statin-treated patients in Greece. Angiology. 2012;63(3):184-193.

22. Horgan S, Crowley J, Feely J, McAdam B, Shanahan E, Vaughan C. Prevalence of dyslipidaemia in statin-treated patients in Ireland: Irish results of the DYSlipidaemia International Study (DYSIS). Ir J Med Sci. 2011;180(2):343-349.

23. Goodman SG, Langer A, Bastien NR, et al. Prevalence of dyslipidemia in statin-treated patients in Canada: results of the DYSlipidemia International Study (DYSIS). Can J Cardiol. 2010;26(9):e330-e335.

24. Gonzalez-Juanatey JR, Millan J, Alegria E, Guijarro C, Lozano JV, Vitale GC. [Prevalence and characteristics of lipid abnormalities in patients treated with statins in primary and secondary prevention in Spain. DYSIS-Spain Study]. Rev Esp Cardiol. 2011;64(4):286-294. Spanish.

25. Gitt AK, Junger C, Smolka W, Bestehorn K. Prevalence and overlap of different lipid abnormalities in statin-treated patients at high cardiovascular risk in clinical practice in Germany. Clin Res Cardiol. 2010;99(11):723-733.

26. da Silva PM, Cardoso SM. Persistent lipid abnormalities in patients treated with statins: Portuguese results of the Dyslipidemia International Study (DYSIS). Rev Port Cardiol. 2011;30(1):47-63.

27. Grundy SM, Cleeman JI, Merz CN, et al. Implications of recent clinical trials for the National Cholesterol Education Program Adult Treatment Panel III guidelines. Circulation. 2004;110(2):227-239.

28. Roberts WC. The rule of 5 and the rule of 7 in lipid-lowering by statin drugs. Am J Cardiol. 1997;80(1):106-107.

29. Catapano AL, Reiner Z, De Backer G, et al. ESC/EAS guidelines for the management of dyslipidaemias. The Task Force for the management of dyslipidaemias of the European Society of Cardiology (ESC) and the European Atherosclerosis Society (EAS). Atherosclerosis. 2011;217(1): $3-46$.

30. Eckel RH, Kahn SE, Ferrannini E, et al. Obesity and type 2 diabetes: what can be unified and what needs to be individualized? J Clin Endocrinol Metab. 2011;96(6):1654-1663.

31. Willi C, Bodenmann P, Ghali WA, Faris PD, Cornuz J. Active smoking and the risk of type 2 diabetes: a systematic review and meta-analysis. JAMA. 2007;298(22):2654-2664.

32. Dyke J. Old habits die hard - smoking ban struggling in Lebanon. Executive. 2013. Available from: http://www.executive-magazine.com/ economics-policy/smoking-ban-lebanon-failing/5541. Accessed March 5, 2014.

33. Bandgar TR, Faruqui AA. Managing dyslipidaemia: evolving role of combination therapy. J Indian Med Assoc. 2011;109(8):549-552.

34. Eber B, Lautsch D, Fauer C, et al. Can LDL-cholesterol targets be achieved in a population at high risk? Results of the non-interventional study ACT II. Curr Med Res Opin. 2012;28(9):1447-1454.

35. Ito MK. Dyslipidemia: management using optimal lipid-lowering therapy. Ann Pharmacother. 2012;46(10):1368-1381.

36. Toth PP, Barter PJ, Rosenson RS, et al. High-density lipoproteins: a consensus statement from the National Lipid Association. J Clin Lipidol. 2013;7(5):484-525.

37. Wierzbicki AS, Clarke RE, Viljoen A, Mikhailidis DP. Triglycerides: a case for treatment? Curr Opin Cardiol. 2012;27(4):398-404.

38. Investigators A-H, Boden WE, Probstfield JL, et al. Niacin in patients with low HDL cholesterol levels receiving intensive statin therapy. N Engl J Med. 2011;365(24):2255-2267. 


\section{Publish your work in this journal}

Vascular Health and Risk Management is an international, peerreviewed journal of therapeutics and risk management, focusing on concise rapid reporting of clinical studies on the processes involved in the maintenance of vascular health; the monitoring, prevention and treatment of vascular disease and its sequelae; and the involvement of metabolic disorders, particularly diabetes. This journal is indexed on PubMed Central and MedLine. The manuscript management system is completely online and includes a very quick and fair peer-review system, which is all easy to use. Visit http://www.dovepress.com/ testimonials.php to read real quotes from published authors.

Submit your manuscript here: http://www.dovepress.com/vascular-health-and-risk-management-journal 